T. Seramak ${ }^{1}$ K. Zasińska ${ }^{1,2^{*}}$, A. Zieliński ${ }^{1}$, J. Andryskowski ${ }^{3}$ A. AndryskowskaIgnaczak $^{3}$, M. Motyl ${ }^{3}$

${ }^{1}$ Gdansk University of Technology, Faculty of Mechanical Engineering, Department of Materials and Welding Engineering, 11/12 Narutowicza, 80-233 Gdańsk, Poland

${ }^{2}$ Gdansk University of Technology, Faculty of Mechanical Engineering, Department of Machine Design and Motor Vehicles, 11/12 Narutowicza, 80-233 Gdańsk, Poland

${ }^{3}$ Prosthetic Laboratory Jerzy Andryskowski, Obrońców Wybrzeża 32, 80-317 Gdańsk, Poland

*katzasin@pg.gda.pl

\title{
PROSTHETIC ELEMENTS MADE OF THE Ti-13Zr-13Nb ALLOY BY SELECTIVE LASER MELTING First optimization of the process parameters
}

\begin{abstract}
The fabrication of the prosthetic foundations and bridges from the Ti-13Zr-13Nb alloy is described. The process was started from CAD/CAM design of 3D models of the foundations based on scanning of patient's mouth. Next, 3D models were transformed into *.stl files for the manufacturing stage and then the manufacturing process by means of the selective laser melting with the SLM Realizer 100 equipment was made. The intrinsic structure of the obtained parts was investigated with X-ray microtomography. The observed imperfections in the foundation's internal structure can be eliminated by a proper setting of the laser melting process. The thermal stresses, which resulted of the temperature change during melting and caused the bending of titanium made bridges, were eliminated at a design stage.
\end{abstract}

Keywords: foundations and bridges, rapid prototyping, selective laser melting, titanium alloys

\section{INTRODUCTION}

The 3D printing of metallic parts is usually made with the laser beam. For medical purposes, the selective laser melting (SLM), selective laser sintering (SLS) and other variants of rapid prototyping by an additive method were investigated $[1,2]$. The main aims were to obtain different sintered alloys and composites and to optimize the process parameters.

The variety of $\mathrm{Ti}$ alloys was so far manufactured. Vrancken [3] obtained the Ti-6A-14V ELI powder mixed with $10 \mathrm{wt} \%$ of Mo powder. The effect of the processing parameters on the quality and mechanical properties of a biomedical titanium alloy (Ti-24Nb-4Zr- $8 \mathrm{Sn}$ ) scaffolds fabricated using selective laser melting was demonstrated in [4]. In [5] new Ti-Re alloys were developed consolidating mixtures of powders of both metals. Zhou et al. [6] obtained a novel titanium alloy (Ti-5.5Al-3.4Sn-3.0Zr-0.7Mo-0.3 Si-0.4Nb-0.35 Ta) with 
a relative density of $99.34 \%$ under the condition of $140 \mathrm{~W}$ laser power and $400 \mathrm{~mm} / \mathrm{s}$ scanning speed. Fischer [7] manufactured the Ti-Nb alloy by SLM on powder bed of a mixture of $\mathrm{Ti}$ and $\mathrm{Nb}$ elemental powders (with $26 \mathrm{at} \% \mathrm{Nb}$ ). Yan et al. [8] developed new biocompatible Ti-15Ta-xZr (1.5, 5.5, 10.5 and $15.5 \mathrm{wt} \%$ of $\mathrm{Zr}$ ) alloys fabricated by selective laser melting. However, this research focused on selective laser melting of the Ti-13Zr-13Nb seems the first for this alloy. Ishimoto et al. [9] successfully achieved the two types of distinct texture control in low-modulus beta-type $\mathrm{Ti}-15 \mathrm{Mo}-5 \mathrm{Zr}-3 \mathrm{Al}$ alloy products using selective laser melting. Wei et al. [10] made the selective laser melting of Ti-5Al-2.5Sn -Ti.

As concerns the process optimization, Maji et al. [11] made the customized femoral prosthesis through computed tomography (CT)-3D CAD-RP-rapid tooling (RT)-investment casting (IC) route using a stereolithography apparatus (SLA-250) RP machine. A similar prosthesis was also developed through conventional CT-CAD-CAM-CNC, using RP models to check the fit before machining. Joguet et al. [12] demonstrated that SLM fitted perfectly with the T40 and Co-Cr-Mo part manufacturing. Chen et L. [13] proposed the zig-zag laser path strategy for the SLM make Ti-6Al-4V bulk samples to achieve the appropriate hardness and electrochemical resistance for the X-, Y- and Z-planes.

The different methods were combined with SLM manufacturing. In [14] fused deposition modeling (FDM) and direct metal laser sintering (DMLS) were used. In [15] the Co-Cr dental alloy samples were made with two different technologies, conventional casting method (CCM) and additive direct metal laser sintering technology (DMLS). The CCM samples had a dense, irregular dendritic mesh, typical for the metallic phase of the $\mathrm{Co}-\mathrm{Cr}$ dental alloy. The DMLS samples possessed more homogenous and more compact structure. Conradie et al. [16] proposed for the Ti-6Al-4V alloy the combination of selective laser melting (SLM) and 5-axis CNC milling to produce parts from titanium powder. The SLM was in [17] joined with hot isostatic pressing (HIPS) to manufacture parts from the Ti-6Al-4V alloy.

The additional heat treatment of the parts obtained by SLM method was sometimes also proposed. Zhang et al. [18] improved the mechanical properties of the Ti-6Al-4V alloy prepared by selective laser melting by the precision forging conducted at $950^{\circ} \mathrm{C}$. In other work [19] the high cooling rate of the Ti-6Al-4V after selective laser melting generated fine grains. Therefore, tensile strength and hardness increased along with a reduction in ductility. The subsequent recrystallization annealing brought out the best combination of ductility, strength, and hardness for the SLM manufactured parts.

Dental and maxillofacial implants and prosthetic goods were also developed with using SLM method. The SLM was used to make the dental implants [20]; the surface treatment via laser-gas-nitriding was applied to achieve better wear resistance. According to [21], the first patient fitted titanium (Ti) complete denture base plate was fabricated by integrating the technologies of computer-aided design, the computer aided manufacture (CAD/CAM) and rapid laser forming (LRF). Yang et al. [22] fabricated the customized brackets directly by SLM method, using 316L stainless steel and optimized shape accuracy, dimensional accuracy and density for orthodontic production. In other work [23], the thin titanium alloy frameworks for a complete maxillary denture was made with a selective laser melting system.

The porous implants may also be perfectly made with SLM technique. Among others, Chen et al. [24] developed the porous Ti-6Al-4V structures and intended to apply as a replacement of human cortical and cancellous bones, manufactured by SLM. The CAD designed structures contained various porosity levels in the range from $40 \%$ to $80 \%$, with pore sizes from 600 to $1000 \mu \mathrm{m}$, suitable for bone tissue in-growth. The structure samples made by SLM method with $40 \%$ to $70 \%$ porosity matched well with their original CAD 
designs; nevertheless, the samples with CAD-designed $80 \%$ porosity were difficult to achieve.

The necessary quality of SLM made parts depends on some interrelated factors. Each metallic material, and in particular alloy has different melting temperatures, diffusion rate at process temperature, thermal conductivity and expansion coefficients. The powders may have different granulations and particle shapes. The different laser power input, laser beam scanning speed, and other parameters may be optimized to obtain the precise dimensions, the negligible porosity, and the reasonable surface roughness of the made parts. Tolochko et al. [25] made the laser sintering of Ti powder of 63-315 $\mu \mathrm{m}$ particle diameter with the $\mathrm{Nd}$ : YAG laser beam with a diameter of 2.7-5.3 mm and a power of 10-100 W focused on a bed of loose Ti powder for $10 \mathrm{~s}$ in a vacuum. Vandenbroucke and Kruth [1] optimized SLM parameters resulting in densities up to 99.98 percent for titanium. Strength and stiffness, corrosion behavior, and process accuracy fulfill requirements for medical and dental parts, which can be produced efficiently and with high precision. Marcu et al. [26] manufactured the Ti-6Al-7Nb with hydroxyapatite (HAp) using a laser power of $50 \mathrm{~W}$. Li et al. [27] in the study of manufacturing by SLM method used two different laser powers: high laser power 250

and low laser power $50 \mathrm{~W}$. Recently, Wysocki et al. [28] proposed manufacturing process by SLM method from commercially pure titanium in a regulated reactive atmosphere with a slight addition of oxygen $(0.2-0.4$ vol.\%) to enhance the mechanical properties of the material.

In the presented work the SLM method was used to produce the prosthetic foundations and bridges for dental crowns made of not yet used for such purpose titanium alloy. So far such foundations are produced by precision milling of $\mathrm{Co}-\mathrm{Cr}$ alloy or by the 3D printing using the corundum ceramics. The first solution is time-consuming and generates a lot of metallic wastes; the second allows to produce the foundations of a high quality, but seems very expensive and brittle. This paper aimed to show our results of the manufacturing the dental prosthetic bridges and crowns by selective laser melting and to indicate the more important process determinants.

\section{METHOD AND EXPERIMENTS}

For the research the Ti-13Nb-13Zr alloy was chosen because of its high biocompatibility with human organism, high corrosion resistance, appropriate tensile strength and fatigue strength, an elastic modulus ( $79 \mathrm{GPa}$ ) that is closer to the Young's modulus of a human bone and contains no harmful elements for human body. Beside, among the mostly used titanium biomaterials, technical titanium has too low mechanical strength, and widely used Ti-6Al-4V and Ti-6Al-7Nb alloys contain elements potentially dangerous for human health - aluminum and vanadium.

The powder for a SLM Realizer 100 printer was obtained from $\mathrm{Ti}-13 \mathrm{Zr}-13 \mathrm{Nb}$ alloy (Ti 13.0, Nb 13.0, Fe 0.005, C 0.004, N 0.019, O $0.011 \mathrm{wt} \%$ ) in a shape of wire of $3.25 \mathrm{~mm}$ in diameter. The powder was obtained by through plasma jet spraying process (by Advanced Powders and Coating Inc., Boisbriand, Québec, Canada). The plasma-atomized spherical powder was sieved and separated into different powder fractions. For the melting and sintering, the powder fraction of a particle size below $50 \mu \mathrm{m}$ was chosen. 
The whole procedure to make individually designed medical parts and implants by SLM method was composed of several stages. It was started from the designing of the implant based on a scan of a patients' mouth with an intraoral scanner. The scans were then transformed into 3D models. The 3D models were subsequently changed into *.stl models used in any 3D printer. In the presented research the SLM Realizer 100 equipment (printer) was used. Then, the process of foundations manufacturing was started from the obtaining of the 3D models. Next, 3D models were transformed into *.stl files with using the CAD software (which is a part of the 3Shape Dental System Suite) and imported into the CAMBridge (3Shape) software in order to generate supports necessary in 3D printing. Models (foundations) with supports finally were cut into layers of a $25 \mu \mathrm{m}$ suitable for the used in SLM Realizer equipment (3D printer).

The SLM process was performed at different process parameters. Finally, the best process parameters were found as: laser power at building the parts contour was in range of $45-55 \mathrm{~W}$, laser power at filling the contour was in range of 55-75 W, the spot size of the laser beam was equal to $0.13 \mathrm{~mm}$, layer thickness $0.25 \mu \mathrm{m}$, oxygen level inside the working chamber was $0.2 \%$, the working chamber was filled with argon as a protective atmosphere, the base plate temperature during process was $200^{\circ} \mathrm{C}$. The base plate was made of technical titanium.

The assessment of the influence of SLM process parameters on the shape, dimensions, quality, matching the degree of the obtained foundations and the state of their surface was conducted using computer X-ray microtomography $(\mu \mathrm{CT})$.

\section{RESULTS AND DISCUSSION}

Fig. 1 shows the prosthetic foundations made by SLM method. Fig. 2 and Fig. 3 shows a single bridge (foundation) before and after sand-blasting with glass beads of a diameter of a $50 \mu \mathrm{m}$. Fig. 4 presents the results of the investigations the real prosthetic bridge reconstructed using the $\mu$ CT method obtained by SLM and treated with sand-blasting.

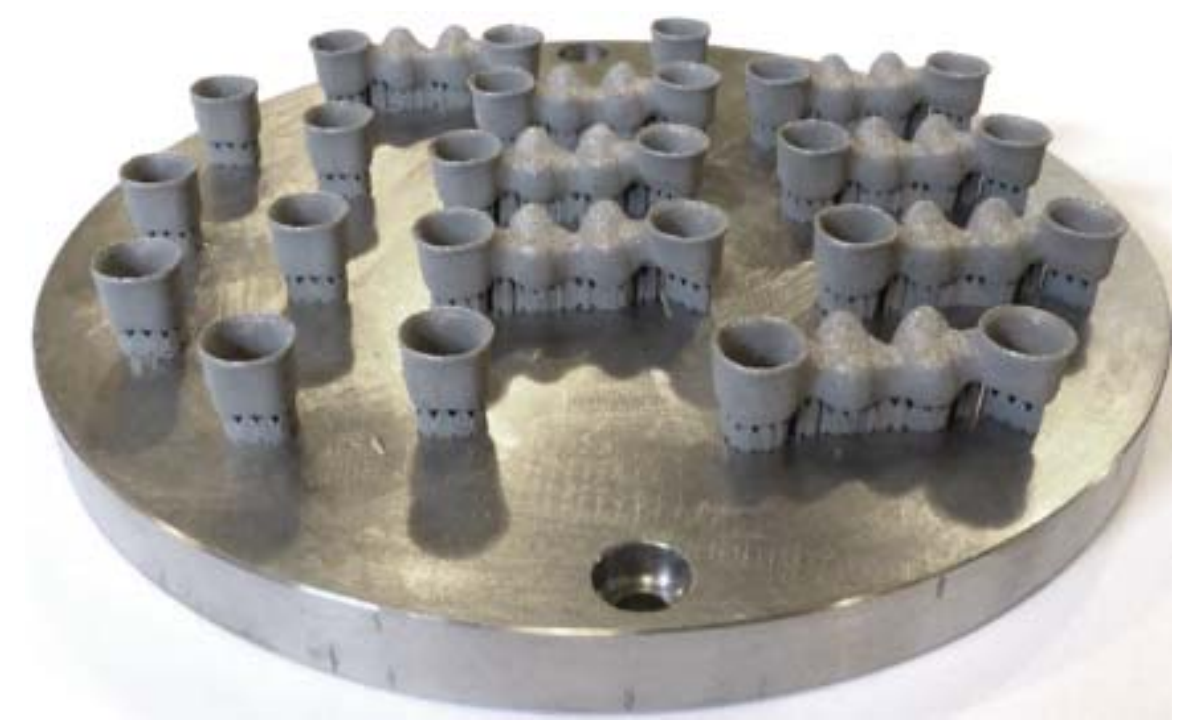

Fig. 1. The prosthetic foundations (crowns and bridges) on the titanium base plate obtained by selective laser melting method (SLM) 


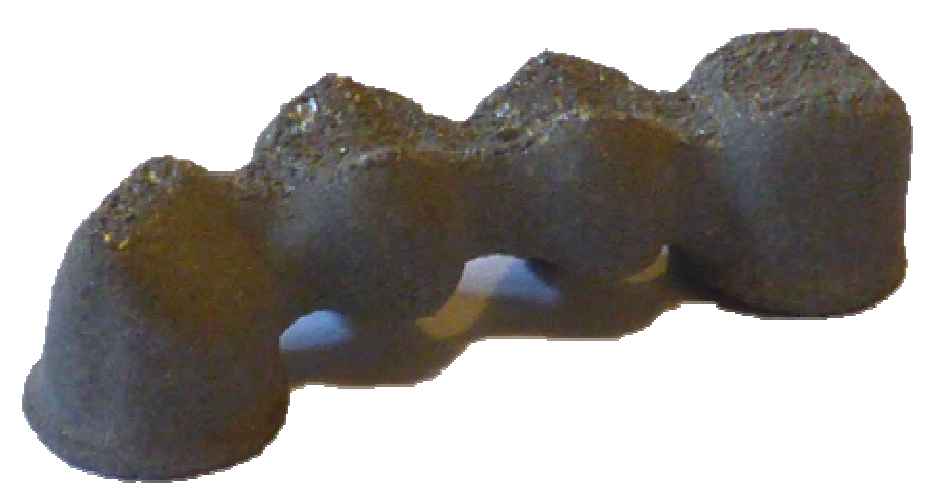

Fig. 2. The prosthetic bridge obtained by selective laser melting method (SLM) before sandblasting

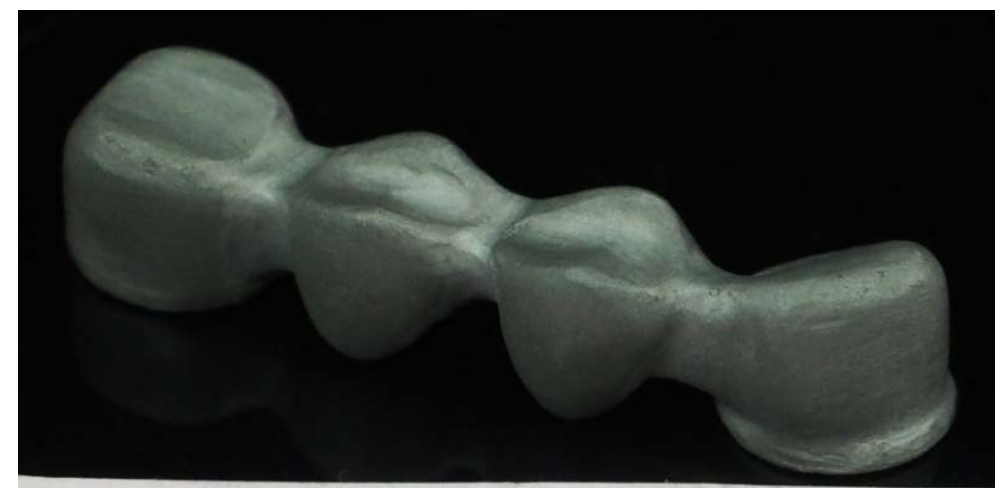

Fig. 3. The prosthetic bridge obtained by selective laser melting method (SLM) after sandblasting

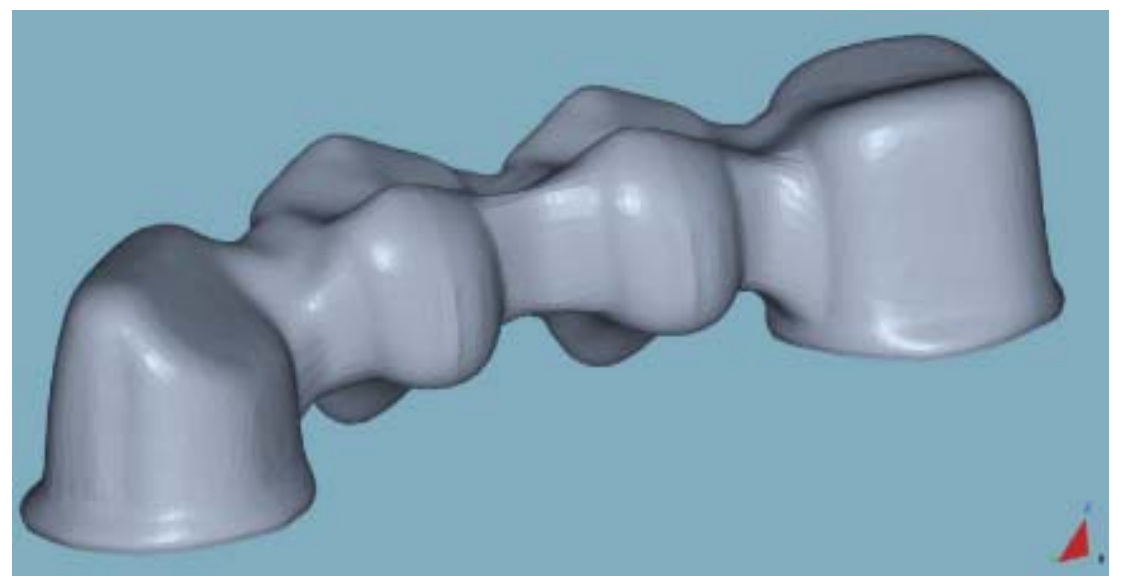

Fig. 4. The result of reconstruction of the prosthetic bridge obtained using $\mu \mathrm{CT}$. The prosthetic bridge obtained by selective laser melting method (SLM) and after sand-blasting

During SLM manufacturing process of the single foundations, the main problem was to obtain the very precise dimensions of the printed part with the substantially high density. At the beginning of trial-and-attempt tests, the dimensions of a real, printed-out prosthetic foundations did not correspond to the dimensions of their virtual CAD models). The probably 
reason was the use of an tested $\mathrm{Ti}$ alloy which has a high shrinkage and a low homogeneity in chemical composition. Therefore in the next step of research, during the specimens design, the decrease of the parts dimensions was taken into account, and the SLM process itself was performed at relatively low rate in order to allow faster diffusion and better mixing of elements which affected in increasing of the printed out foundations fitting degree to theirs virtual CAD models.

For printed bridges, another problem was encountered. The shape of the real bridges obtained by means of a SLM Realizer 100 printer was deviated from its shape the designed in CAD because of huge thermal stresses after sintering process. To eliminate the problem of a shape deformation, after trials and comparisons of the real and virtual CAD models of the obtained foundations, the stress level and its shape deformations were taken into account in design process of the future prosthetic bridges.

The foundations and bridges should have a very small number of voids inside a structure, which may also be expressed as the density that should be very close to that of solid materials. After many attempts with SLM process parameters, we achieved over $98 \%$ of a theoretical casted metal density with almost no voids in printed out parts.

\section{CONCLUSIONS}

The selective laser melting method can be used to obtain very precise prosthetic foundations made of the Ti-13Zr-13Nb alloy.

The development of applicable and suitable manufacturing parameters by SLM method needs to take into account the used material, its thermal conductivity, and thermal stresses, which occurs after melting process by laser beam.

\section{ACKNOWLEDGMENTS}

The financial assistance for this research, made within the project TANGO1/266396/NCBR/2015, was obtained from the National Center for Research and Development, Poland. The project was performed in cooperation with Prosthetic Laboratory Jerzy Andryskowski, Gdansk.

\section{REFERENCES}

1. Zhang L.C., Attar H.: Selective laser melting of titanium alloys and titanium matrix composites for biomedical applications: A review. Advanced Engineering Materials 18 (2016) 463-465.

2. Vrancken B., Thijs L., Kruth J.-P., Van Humbeeck J.: Microstructure and mechanical properties of a novel $\beta$ titanium metallic composite by selective laser melting. Acta Materialia 68 (2014) $150-158$.

3. Liu Y.J., Li X.P., Zhang L.C., Sercombe T.B.: Processing and properties of topologically optimised biomedical Ti-24Nb-4Zr-8Sn scaffolds manufactured by selective laser melting. Materials Science and Engineering A 642 (2015) 268-278. 
4. Chlebus E., Kuźnicka B., Dziedzic R., Kurzynowski T.: Titanium alloyed with rhenium by selective laser melting. Materials Science and Engineering A 620 (2015) 155-163.

5. Zhou Y., Wen S.F., Song B. et al.: A novel titanium alloy manufactured by selective laser melting: Microstructure, high-temperature oxidation resistance. Materials and Design 89 (2016) 1199-1204.

6. Fischer M., Joguet D., Robin G. et al.: In situ elaboration of a binary Ti-26Nb alloy by selective laser melting of elemental titanium and niobium mixed powders. Materials Science and Engineering C 62 (2016) 852-859.

7. Yan L., Yuan Y., Ouyang L. et al.: Improved mechanical properties of the new Ti-15Ta-xZr alloys fabricated by selective laser melting for biomedical application. Journal of Alloys and Compounds 688 (2016) 156-162.

8. Ishimoto T., Hagihara K., Hisamoto K. et al.: Crystallographic texture control of beta-type Ti$15 \mathrm{Mo}-5 \mathrm{Zr}-3 \mathrm{Al}$ alloy by selective laser melting for the development of novel implants with a biocompatible low Young's modulus. Scripta Materialia 132 (2017) 34-38.

9. Wei K., Wang Z., Zeng X.: Preliminary investigation on selective laser melting of Ti-5Al-2.5Sn C-Ti alloy: From single tracks to bulk 3D components. Journal of Materials Processing Technology 244 (2017) 73-85.

10. Maji P.K., Banerjee A.J., Banerjee P.S., Karmakar S.: Additive manufacturing in prosthesis development - a case study. Rapid Prototyping Journal 20 (2014) 480-489.

11. Joguet D., Costil S., Liao H., Danlos Y.: Porosity content control of CoCrMo and titanium parts by Taguchi method applied to selective laser melting process parameter. Rapid Prototyping Journal 22 (2016) 20-30.

12. Chen L.Y., Huang J.C., Lin C.H. et al.: Anisotropic response of Ti-6Al-4V alloy fabricated by 3D printing selective laser melting. Materials Science and Engineering A 682 (2017) 389-395.

13. Fantini M., De Crescenzio F., Ciocca L., Persiani F.: Additive manufacturing to assist prosthetically guided bone regeneration of atrophic maxillary arches. Rapid Prototyping Journal 24 (2015) 705-715.

14. Lapcevic A.R., Jevremovic D.P., Puskar T.M. et al.: Comparative analysis of structure and hardness of cast and direct metal laser sintering produced Co-Cr alloys used for dental devices", Rapid Prototyping Journal 22 (2016) 144-151.

15. Conradie P.J.T., Dimitrov D., Oosthuizen G.A.et al.: Comparative assessment of process combination for Ti6A14V components. Rapid Prototyping Journal 23 (2017) 624-632.

16. Hassanin H., Essa K., Qiu C. et al.: Net-shape manufacturing using hybrid selective laser melting/hot isostatic pressing. Rapid Prototyping Journal 23 (2017), iss. 4, in press.

17. Zhang Q., Liang Z.-L., Cao M. et al.: Microstructure and mechanical properties of Ti6A14V alloy prepared by selective laser melting combined with precision forging. Trans. Nonferrous Met. Soc. China 27 (2017) 1036-1042.

18. Khorasani A.M., Gibson I., Goldberg M., Littlefair G.: On the role of different annealing heat treatments on mechanical properties and microstructure of selective laser melted and conventional wrought Ti-6Al-4V. Rapid Prototyping Journal 23 (2017) 295-304.

19. Santos E., Osakada K., Shiomi M. et al.: Fabrication of titanium dental implants by selective laser melting. Proc. SPIE 5662, 5th Intl. Symp. Laser Precision Microfabr. 2004.

20. Gao B., Wu J., Zhao X., Tan H.: Fabricating titanium denture base plate by laser rapid forming. Rapid Prototyping Journal 15 (2009) 133-136. 
21. Yang Y., Lu J.-B., Luo Z. Y., Wang D.: Accuracy and density optimization in directly fabricating customized orthodontic production by selective laser melting. Rapid Prototyping Journal 18 (2012) 482-489.

22. Kanazawa M., Iwaki M., Minakuchi S., Nomura N.: Fabrication of titanium alloy frameworks for complete dentures by selective laser melting. Journal of Prosthehtic Dentistry 112 (2014) 14411447.

23. Chen S.Y., Huang J.C., Pan C.T. et al.: Microstructure and mechanical properties of open-cell porous Ti-6Al-4V fabricated by selective laser melting. Journal of Alloys and Compounds 713 (2017) 248-254.

24. Tolochko N.K., Arshinov M.K., Gusarov A.V. et al.: Mechanisms of selective laser sintering and heat transfer in Ti powder. Rapid Prototyping Journal 9 (2003) 314-326.

25. Marcu T., Menapace C., Girardini L. et al.: Selective laser melting of Ti6Al7Nb with hydroxyapatite addition. Rapid Prototyping Journal 20 (2014) 301-310.

26. Li X.P., Van Humbeeck J., Kruth J.P., Selective laser melting of weak-textured commercially pure titanium with high strength and ductility: A study from laser power perspective. Materials and Design 116 (2017) 352-358.

27. Wysocki B., Maja P., Krawczynska A. et al.: Microstructure and mechanical properties investigation of CP titanium processed by selective laser melting (SLM). Journal of Materials Processing Technology 241 (2017) 13-23. 